\title{
Double-endoscope assisted endoscopic submucosal dissection for treating gastric neuroendocrine tumor.
}

A middle-aged man was found to have a solitary lesion about $5 \mathrm{~mm}$ in diameter on the greater curvature of the lower gastric body during routine endoscopic examination ( $\triangleright$ Fig. 1 a). Biopsy pathology plus immunohistochemistry reported a neuroendocrine tumor G2. A doubleendoscope assisted endoscopic submucosal dissection (ESD) procedure was used to remove the tumor ( $\vee$ Video 1 ).

The procedure began with cautery markings around the tumor using a dual knife, followed by submucosal injection ( $\vee$ Fig. $1 \mathbf{b}$ ) and incision of the oral side of the covering mucosa ( $\vee$ Fig. 1 c). In order to facilitate subsequent tumor dissection, a second endoscope equipped with a snare was applied to provide additional traction on the covering mucosa to aid in submucosal dissection ( $\triangleright$ Fig.1 d). The second endoscope does not need its own light source since the main endoscope can guide the snare to grasp the mucosa and the rest is simply to maintain traction. The snare can be pulled or pushed by the second endoscope in multiple directions, providing better exposure than the widely used "clip-and-thread" method, where the clip attached to the mucosa can be pulled only toward the oral side.
After tumor removal, the wound surface was carefully examined for potential perforation; electric forceps were used to coagulate visible bleeding ( $\triangleright$ Fig. 1 e,f). The whole procedure took only about 20 minutes thanks to effective exposure. To our knowledge, this is the second report of endoscopic resection of a gastric submucosal tumor aided by a second endoscope [1] and the first report of such a procedure without a second light source.

Endoscopy_UCTN_Code_TTT_1AO_2AG
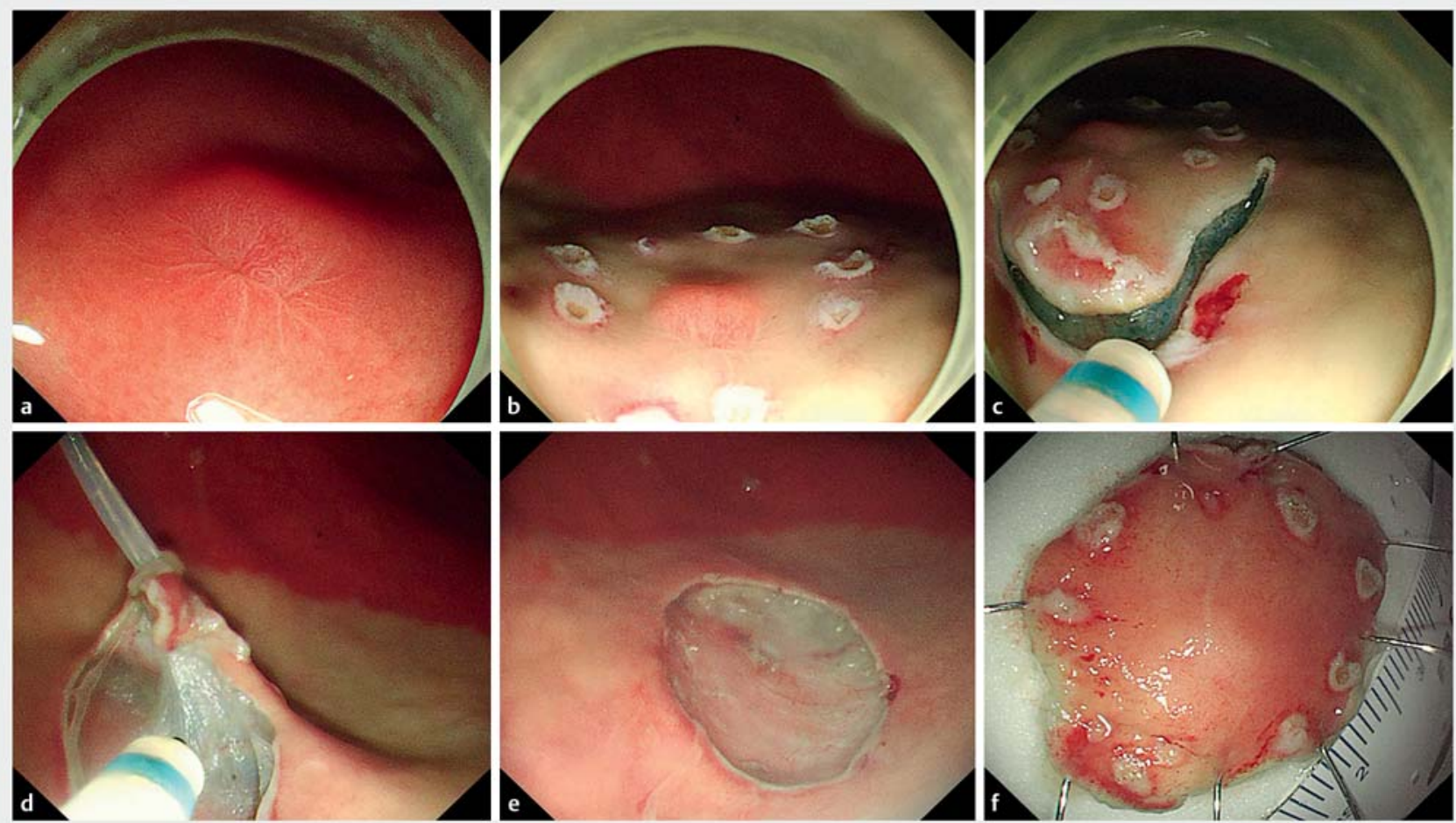

- Fig. 1 a Submucosal lesion on the greater curvature of the lower gastric body with post-biopsy scar on covering mucosa. b Cautery markings and submucosal injection around the tumor. $\mathbf{c}$ Initial incision of covering mucosa on the oral side of the tumor. $\mathbf{d}$ Traction of the covering mucosa by a snare controlled by a second endoscope. e Clean wound surface after tumor removal. f Resected tumor specimen. 


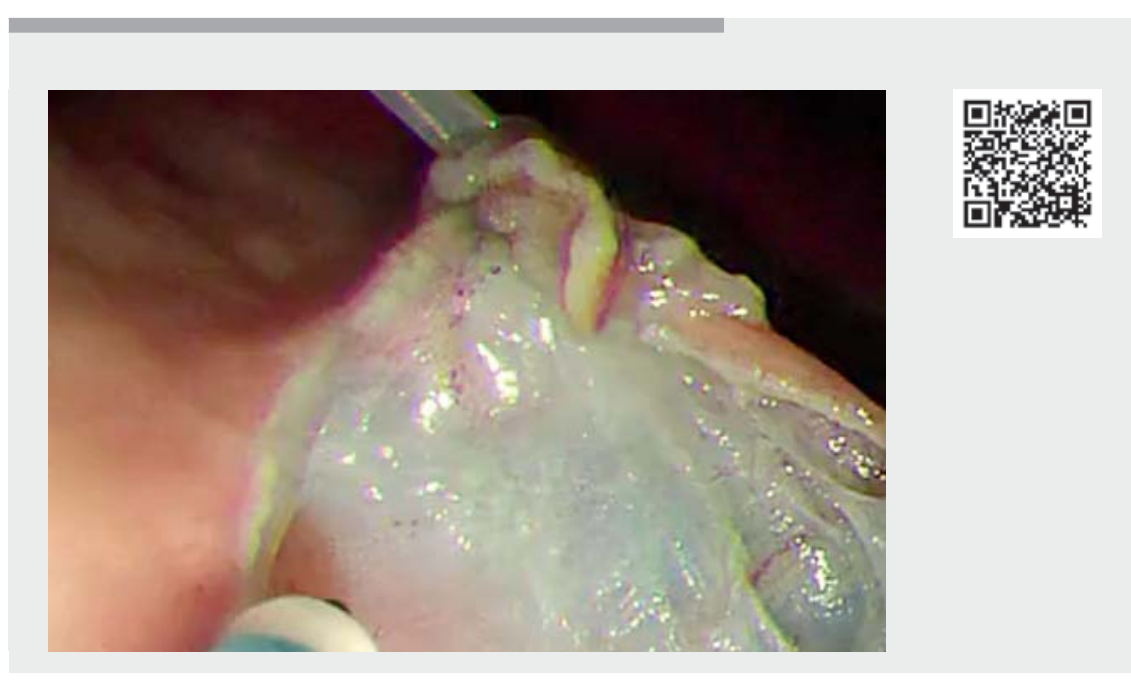

$\checkmark$ Video 1 Double-endoscope assisted endoscopic submucosal dissection for treating gastric neuroendocrine tumor.

\section{Competing interests}

The authors declare that they have no conflict of interest.

The authors

Jiaoyang Lu ${ }^{1,2}$, Peng Wang ${ }^{2}$, Rui ji² , Xuefeng Lu $^{2}$

1 School of Medicine, Shandong University, Jinan, Shandong, China

2 Department of Gastroenterology, Qilu Hospital, Shandong University, Jinan, Shandong, China
Bibliography

Endoscopy 2022; 54: E342-E343

DOI 10.1055/a-1540-6226

ISSN 0013-726X

published online 19.7.2021

(C) 2021. Thieme. All rights reserved.

Georg Thieme Verlag KG, Rüdigerstraße 14, 70469 Stuttgart, Germany

\section{ENDOSCOPY E-VIDEOS}

https://eref.thieme.de/e-videos

回题 Endoscopy E-Videos is an open access online section, 靣程: reporting on interesting cases and new techniques in gastroenterological endoscopy. All papers include a high quality video and all contributions are freely accessible online. Processing charges apply (currently EUR 375), discounts and wavers acc. to HINARI are available.

This section has its own submission website at

https://mc.manuscriptcentral.com/e-videos

\section{Reference}

[1] Çolak Ş, Gürbulak B, Çakar E et al. Resection of mucosal and submucosal gastrointestinal lesions and a double endoscope experience. JSLS 2019; 23: e2018.00096

\section{Xuefeng Lu, MD}

Hospital, Shandong University, Jinan,

Shandong 250012, China

lu0801shanyi@163.com 